\title{
EFEKTIVITAS MODEL PEMBELAJARAN GROUP INVESTIGATION TERHADAP HASIL BELAJAR SISWA PADA MATA PELAJARAN FIQIH KELAS XI
}

\author{
Siti Laylatul Izzah*1 \\ ${ }^{1}$ Mahasiswa Prodi PAI Fakultas Agama Islam Universitas KH. A. Wahab Hasbullah \\ izzahlaylatul18@gmail.com \\ Nurul Afidah, M. Pd.*2 \\ 2Dosen Prodi Pendidikan B.Inggris Fakultas Ilmu Pendidikan \\ Universitas KH. A. Wahab Hasbullah \\ nurulafidah@unwaha.ac.id \\ Amrini Shofiyani, M. Pd.*3 \\ ${ }^{3}$ Dosen Prodi PBA Fakultas Agama Islam Universitas KH. A. Wahab Hasbullah \\ rinishofiyani@unwaha.ac.id
}

\begin{abstract}
The Effectiveness of Group Investigation Learning Models on Student Learning Outcomes in Subjects of Fiqh. The purpose of this research is to find out whether the group investigation learning model class XI MIPA is more effective than the conventional learning model class XI IIS 1 on the learning outcomes of students of class XI Aliah Al-IhsanKalikejambon on Fiqh subjects. The research is in the form of experiments with the type of experiment conducted is quasi-experimental research (Quasy Experiment Research). Based on the results of statistical calculations from the average post-test results of the control class 68.35 and the average post-test results of the experimental class 72.75 obtained calculations using the SPSS program with a significance of significance (Sig 2-tailed) is 0.034 , a significance value of $0.034<0.05$. Then Ho is rejected and Ha is accepted. Thus it can be concluded that there is a significant difference between the results of the post-test of the control class and the experimental class. Thus, it can be said that the teaching and learning process carried out with the group investigation learning model in class XI MIPA is more effective than conventional learning models in class XI IIS 1 on student learning outcomes in the subject of Fiqh.
\end{abstract}

Keywords: Fiqh lessons, Group Investigation, Learning Outcomes.

\section{A. PENDAHULUAN}

Mata pelajaran fiqih merupakan bagian dari mata pelajaran Pendidikan

Agama Islam untuk menyiapkan peserta didik supaya bisa mengenal, memahami, 


\section{Siti Laylatul Izzah, Nurul Afidah, Amrini Shofiyani.}

menghayati, dan mengamalkan hukum Islam dan kemudian dijadikan dasar bagi pandangan hidupnya ( way of life ). Tujuan itu bisa tercapai melalui kegiatan bimbingan, pengajaran, praktik, pengamalan, dan pembiasaan kepada peserta didik.

Tujuan dari pembelajaran bidang studi fiqih adalah untuk memberikan bekal kepada peserta didik agar dapat mengetahui pokok - pokok ajaran Islamdalam mengatur hubungan antar sesama manusia serta ketentuan dalam pelaksanaan dan pengamalan ibadah kepada Allah SWT. Dengan adanya pengamalan itu diharapkan dapat menumbuhkan ketaatan dalam menjalankan hukum Islam. ${ }^{1}$

Pada masa sekarang ini, perubahan dalam dunia pendidikan menjadi tuntutan bagi seorang guru terutama dalam hal proses belajar mengajar. Karena pada saat ini, guru tidak bisa lagi mempertahankan paradigma lama. Adanya perkembangan teori pembelajaran dan hasil-hasil penelitian di bidang pendidikan membuktikan bahwa para guru sebaiknya sudah mengubah paradigma pengajaran dari pola belajar konvensional menjadi pola belajar siswa aktif.

Di zaman sekarang ini metode pembelajaran sudah banyak, tinggal pendidik saja yang memilih metode mana yang cocok dalam proses pembelajaran agar peserta didik tidak merasa jenuh pada saat kegiatan belajar mengajar ( KBM

\footnotetext{
${ }^{1}$ M. Syafiuddin Shobirin dan M. Faridl Darmawan, "Pengembangan Pembelajaran Kitab Kuning Di Pesantren Luhur Malang", dalam Jurnal JoEMS (Jounal of Education and Management Studies). Vol. 2, No. 1, 15-24, 2019.
} 


\section{Efektivitas Model Pembelajaran Group Investigation Terhadap} Hasil Belajar Siswa Pada Mata Pelajaran Fiqih Kelas XI

). ${ }^{2}$ Sehingga peserta didik menjadi lebih semangat dan lebih aktif dari pendidiknya.

Dengan demikian, salah satu metode pembelajaran yang dapat membuat siswa lebih aktif dan tidak merasa jenuh pada saat proses pembelajaran adalah salah satunya dengan menerapkan model pembelajaran berbasis group investigation yang berdasar atas model pembelajaran kooperatif ( Cooperative Learning ). Kooperatif merupakan rangkaian kegiatan belajar yang dilakukan oleh peserta didik yang dibentuk dalam kelompok- kelompok tertentu guna mencapai tujuan pembelajaran yang ditentukan.

Tipe GI (Group Investigation) merupakan salah satu metode dalam pembelajaran kooperatif yang menekankan pada heterogenitas dan kerjasama antar siswa, sementara guru hanyaberperan sebagai fasilitator saja. Dalam model pembelajaran ini peserta didik dituntut untuk saling bekerja sama dengan setiap anggota kelompok untuk memahami bahan pembelajaran dan menyelesaikan tugas. $^{3}$

Manfaat model pembelajaran group investigation terhadap siswa diantaranya yaitu dapat memadukan pengetahuan dan keterampilan, melatih siswa untuk bekerja secara kooperatif ( berkelompok ) dalam memecahkan suatu masalah, meningkatkan hubungan serta kebersamaan antar kelompok karena

\footnotetext{
2 Muhammad Khoirur Roziqin, "Metode-Metode Pendidikan Islam Dalam Mendidik Anak-Anak", dalam Jurnal Eduscope : Jurnal Pendidikan, Pembelajaran dan Teknologi", Vol. 3 no. 1, 2019.

3 Astusi, Alfira Mulya. "Efektivitas Model Pembelajaran Kooperative Tipe Group Investigation Terhadap Peningkatan Kemampuan Investigasi Matematika Siswa" Beta: Jurnal Tadris Matematika, Volume 7 Nomor 1 ( Mei 2014 ) : 3-5, diakses pada 10 Oktober 2019. https://jurnalbeta.ac.id.
} 


\section{Siti Laylatul Izzah, Nurul Afidah, Amrini Shofiyani.}

belajar kooperatif ini memberi kesempatan kepada siswa untuk berinteraksi dengan teman satu tim untuk mencerna atau memahami materi pelajaran. ${ }^{4}$

Berdasarkan hasil pengamatan yang penulis lakukan karena melakukan PPL di Madrasah Aliyah Al - Ihsan Kalikejambon, model pembelajaran yang paling dominan yang digunakan adalah model pembelajaran secara konvensional yaitu metode ceramah, tanya jawab dan pemberian tugas. Dimana metode tersebut dirasa kurang menarik dan kurang memberikan kesempatan bagi siswa untuk berpartisipasi aktif, kurang mengembangkan keterampilan serta kurang mewujudkan interaksi antar peserta didik satu dengan lainnya.

Berdasarkan uraian di atas, maka dilakukan penelitian untuk mengetahui “Efektivitas Model Pembelajaran Group Investigation Terhadap Hasil Belajar Siswa Pada Mata Pelajaran Fiqih Kelas XI MA Al - Ihsan Kalikejambon".

Tujuan dari penelitian ini adalah (1) untuk mengetahui hasil belajar siswa pada kelas kontrol ( XI IIS 1 ) yang diajar menggunakan model pembelajaran konvensional, (2) untuk mengetahui hasil belajar siswa pada kelas eksperimen ( XI MIPA ) yang diajar menggunakan model pembelajaran group investigation, (3) untuk mengetahui apakah ada perbedaan yang signifikan antara model pembelajaran konvensional dengan model pembelajaran group investigation.

\section{B. METODE PENELITIAN}

\footnotetext{
${ }^{4}$ Model Pembelajaran Group Investigation. (Online). http:/ / allforedu.blogspot.com/2012/06/kelebihan-dan-kekuranganpembelajaran html. diakses pada 15 Oktober 2019.
} 


\section{Efektivitas Model Pembelajaran Group Investigation Terhadap}

Hasil Belajar Siswa Pada Mata Pelajaran Fiqih Kelas XI

Metode penelitian yang digunakanadalah jenis penelitian eksperimen semu (Quasi Eksperimen). Dengan populasi dalam penelitian ini adalah siswa kelas XI semester I pada Madrasah Aliyah Al - Ihsan Kalikejambon Tahun Ajaran 2019/2020, yaitu kelas XI MIPA, XI IIS 1, dan XI IIS 2 dengan jumlah siswa 75 orang. Kemudian dalam penelitian ini, sampel yang digunakan adalah kelas XI MIPA dan XI IIS 1. Dimana, kelas XI IIS 1 berjumlah 26 orang sebagai kelas kontrol yang diberi model pembelajaran konvensional dan kelas XI MIPA yang berjumlah 20 orang sebagai kelas eksperimen yang diberi model pembelajaran group investigation.

Teknik pengumpulan data dalam penelitian ini adalah dengan teknik pengukuran tes hasil belajar dengan memberikan skor pada post-test. Adapun alat pengumpul data dalam penelitian ini adalah tes tertulis berupa tes esai (uraian) untuk mendapatkan datapost-test dari responden.

Untuk mengetahui ada tidaknya perbedaan hasil belajar siswa antara kelas eksperimen dan kelas kontrol, maka data yang diperoleh dari tes hasil belajar selanjutnya diolah dengan langkah-langkah sebagai berikut: (1) Memberikan hasil skor post-test siswa pada kelas kontrol ( XI IIS 1 ), (2) Memberikan hasil skor posttest siswa pada kelas eksperimen ( XI MIPA ), (3) Melakukan uji Independent Sampel $\mathrm{T}$ - test dengan program SPSS. Dengan kriteria pengujian sebagai berikut: (a) Terima Ha : jika signifikansi ( 2 - tailed ) $<0.05$, maka terdapat perbedaan yang signifikan antara hasil belajar pada Kelas Eksperimen ( XI MIPA ) dan Kelas 


\section{Siti Laylatul Izzah, Nurul Afidah, Amrini Shofiyani.}

Kontrol ( XI IIS 1 ) (b) Tolak Ho : jika signifikansi ( 2 - tailed )>0.05, maka tidak terdapat perbedaan yang signifikan antara hasil belajar pada Kelas Eksperimen ( XI MIPA ) dan Kelas Kontrol (XI IIS 1).

\section{HASIL dan PEMBAHASAN}

\section{Hasil}

Miftahul Huda (2013:292) menyatakan bahwa metode Group Investigation (GI) pertama kali dikembangkan oleh Sharan ( 1976 ) yang merupakan salah satu metode kompleks dalam pembelajaran kelompok yang mengharuskan peserta didik untuk menggunakan kemampuan berpikir tingkat tinggi. Padaprinsipnya, dalam konteks pembelajaran kooperatif, metode GI (Group Investigation) tetap menekankan pada heterogenitas dan kerjasama antar peserta didik. ${ }^{5}$

Pada proses pembelajaran model Group Investigation, siswa akan dibagi menjadi beberapa kelompok kecil. Ketua kelompok akan dipanggil untuk mengambil satu materi yang akan dibahas dalam kelompoknya dan setiap kelompok akan membahas materi yang berbeda. Setelah itu ketua kelompok akan kembali kedalam kelompoknya untuk memulai melakukan diskusi berdasarkan materi yang telah ditentukan. Setelah diskusi berakhir, bersama kelompok nya masing - masing menyampaikan hasil diskusinya dihadapan

\footnotetext{
5 Huda, M. (2013). Model-Model Pembelajaran dan Pengajaran. Yogyakarta: Pustaka Belajar. Dalam Adinata, Ferry. “(Efektivitas Model Pembelajaran Group Investigation Untuk Meningkatkan Hasil Belajar Siswa Pada Mata Pelajaran Ekonomi)." (Artikel Penelitian Universitas Tanjungpura Pontianak, 2013), diakses pada 13 Oktober 2019. http://jurnal.untan.ac.id/index.php/jpdbp/article/view/3059.
} 
kelompok lain. Kemudian penjelasan akan ditutup dengan tanggapan yang diberikan oleh guru sekaligus kesimpulan dari apa yang disampaikan oleh kelompok tersebut.

Peran pendidik dalam penerapan model pembelajaran ini adalah sebagai motivator, fasilitator dan sebagai sumber belajar. Sebagai motivator, pendidik memberikan dorongan kepada peserta didik baik individu ataupun kelompok untuk mengerjakan tugas dengan penuh rasa percaya diri dan yakin bahwa dia mampu menyelesaikan tugas dengan baik melalui kerjasama yang dibangun dengan solid.

Sebagai fasilitator, pendidik aktif memantau aktivitas peserta didik dalam mengerjakan tugas dan penyajian laporan kelompok. Pendidik harus siap memberikan bantuan jika peserta didik mengalami kesulitan. Diusahakan agar pada saat penyajian laporan kelompok, seluruh peserta didik menyimak dengan baik dan memberikan respon tanggapan atau pertanyaan. ${ }^{6}$

Tujuan dilakukannya penelitian ini adalah untuk mengetahui apakah model pembelajarangroup investigation di kelas XI MIPA lebih efektif dibandingkan dengan model pembelajaran konvensional di kelas XI IIS 1 terhadap hasil belajar siswa kelas Madrasah Aliyah Al - Ihsan Kalikejambon. Jumlah sampel dalam penelitian ini adalah orang dengan rincian 20 orang di kelas XI MIPA sebagai kelas eksperimen dan 26 dikelas XI IIS 1 sebagai kelas

${ }^{6}$ Ibid. 


\section{Siti Laylatul Izzah, Nurul Afidah, Amrini Shofiyani.}

kontrol, tetapi menjadi 20 siswa dikarenakan 6 siswa pada saat dilakukan posttest tidak masuk. Dari sampel tersebut diperoleh data skorpost-test siswa yang meliputi: (1) Skor hasil tes siswa pada kelas eksperimen (XI MIPA) yang diajar dengan model pembelajaran group investigation, (2) Skor hasil tes siswa pada kelas kontrol ( XI IIS 1 ) yang diajar dengan model pembelajaran konvensional.

\section{Pembahasan}

Group Statistics

\begin{tabular}{|l|l|r|r|r|r|}
\hline & Kelas & N & \multicolumn{1}{|c|}{ Mean } & Std. Deviation & \multicolumn{1}{c|}{ Std. Error Mean } \\
\hline \multirow{3}{*}{ Hasil Belajar Fiqih } & Kelas XI MIPA & 20 & 72.75 & 5.495 & 1.229 \\
& Kelas XI IIS 1 & 20 & 68.35 & 7.051 & 1.577 \\
\hline
\end{tabular}

\begin{tabular}{|c|c|c|c|c|c|c|c|c|c|c|}
\hline \multicolumn{11}{|c|}{ Independent Samples Test } \\
\hline & & \multicolumn{2}{|c|}{$\begin{array}{l}\text { Levene's Test for Equality of } \\
\text { Variances }\end{array}$} & \multicolumn{7}{|c|}{ t-test for Equality of Means } \\
\hline & & \multirow[b]{2}{*}{$\mathrm{F}$} & \multirow[b]{2}{*}{ Sig. } & \multirow[b]{2}{*}{$t$} & \multirow[b]{2}{*}{ df } & \multirow[b]{2}{*}{ Sig. (2-tailed) } & \multirow{2}{*}{$\begin{array}{c}\text { Mean } \\
\text { Difference }\end{array}$} & \multirow{2}{*}{$\begin{array}{l}\text { Std. Error } \\
\text { Difference }\end{array}$} & \multicolumn{2}{|c|}{$\begin{array}{l}\text { 95\% Confidence Interval of the } \\
\text { Difference }\end{array}$} \\
\hline & & & & & & & & & Lower & Upper \\
\hline Hasil Belajar Figih & $\begin{array}{l}\text { Equal variances } \\
\text { assumed }\end{array}$ & .132 & .718 & 2.201 & 38 & .034 & 4.40000 & 1.99888 & .35348 & 8.44652 \\
\hline & $\begin{array}{l}\text { Equal variances not } \\
\text { assumed }\end{array}$ & & & 2.201 & 35.861 & .034 & 4.40000 & 1.99888 & .34554 & 8.45446 \\
\hline
\end{tabular}

Hasil uji-t menggunakan SPSS didapatakan nilai signifikansi (Sig 2tailed) adalah 0,034. Nilai signifikansi 0,034<0,05, maka Ho ditolak dan Ha diterima. Dari hasil tersebut maka terdapat perbedaan hasil nilai post-test siswa untuk kelas eksperimen (XI MIPA) dan kelas kontrol (XI IIS 1).

Bahwa kelas eksperimen lebih tinggi hasil post-test dari pada kelas kontrol, kelas eksperimen dengan model pembelajaran group investigation dan kelas control dengan model pembelajaran konvensional. Jadi model pembelajaran group investigation lebih efektif dari pada model pembelajaran 
konvensional pada hasil belajar siswa pada mata pelajaran Fiqih kelas XI Madrasah Aliyah Al-Ihsan Kalikejambon.

Dengan demikian, penelitian dengan menggunakan model pembelajaran group investigation dapat meningkatkan hasil belajar siswa sejalan teori yang mengatakan bahwa model pembelajaran group investigation adalah salah satu pembelajaran yang dapat membidik siswa berpikir kritis dan meningkatkan kerja sama antar siswa dalam bentuk kerja kelompok. Model pembelajaran Group investigation memuat empat komponen penting yaitu investigasi, interaksi, interpretasi, dan motivasi intrinsik. Investigasi adalah proses dalam menemukan konsep pada suatu materi. Interaksi adalah cirri khas dari metode pembelajaran kooperatif, yaitu dengan melibatkan siswa dalam bekerja sama pada kelompok-kelompok belajar. Kegiatan interprestasi ditunjukkan dengan mendorong siswa untuk menafsirkan pemecahan masalah yang dipilih secara sintesis dan elaborasi dari ide-ide setiap anggota kelompok. Motivasi intrinsic timbul karena siswa diberi otonomi untuk melakukan proses investigasi.

\section{KESIMPULAN}

Berdasarkan hasil penelitian hasil belajar siswa, dapat ditarik kesimpulan bahwa: (1) Hasil belajar siswa pada kelas Kontrol ( XI IIS 1 ) yang diajar dengan model pembelajaran konvensional menunjukkan skor post-test terendah adalah 50 dan skor tertinggi 80 dengan rata-rata 68,35. (2) Hasil belajar siswa pada kelas eksperimen (XI MIPA) yang diajar dengan model 


\section{Siti Laylatul Izzah, Nurul Afidah, Amrini Shofiyani.}

pembelajaran group investigation menunjukkan skor post-test terendah adalah 65 dan skor tertinggi 80 dengan rata-rata 72,75. (3) Adanya perbedaan yang signifikan antara hasil belajar siswa yang diajar menggunakan model pembelajaran group investigation (XI MIPA) dan yang diajar menggunakan model pembelajaran konvensional (XI IIS 1). Hal ini dapat dilihat dari hasil perhitungan uji statistic uji-t yang diperoleh nilai signifikansi (Sig 2-tailed) adalah 0,034 ,nilai signifikansi 0,034<0,05. Maka Ho ditolak dan Ha diterima. Dengan demikian dapat disimpulkan bahwa terdapat perbedaan yang signifikan antara hasil post-test siswa pada kelas control (XI IIS 1) dan kelas eksperimen (XI MIPA).

\section{E. DAFTAR PUSTAKA}

Adinata, Ferry. "(Efektivitas Model Pembelajaran Group Investigation Untuk Meningkatkan Hasil Belajar Siswa Pada Mata Pelajaran Ekonomi)." (Artikel Penelitian Universitas Tanjungpura Pontianak, 2013), diakses pada 13 Oktober 2019. http://jurnal.untan.ac.id/index.php/jpdbp/article/view/3059.

Astusi, Alfira Mulya. “Efektivitas Model Pembelajaran Kooperative Tipe Group Investigation Terhadap Peningkatan Kemampuan Investigasi Matematika Siswa" Beta: Jurnal Tadris Matematika, Volume 7 Nomor 1 ( Mei 2014 ) : 3-5, diakses pada 10 Oktober 2019. https://jurnalbeta.ac.id.

Huda, M. (2013). Model-Model Pembelajaran dan Pengajaran. Yogyakarta: Pustaka Belajar.

Khoirur Roziqin, Muhammad. "Metode-Metode Pendidikan Islam Dalam Mendidik Anak-Anak", dalam Jurnal Eduscope : Jurnal Pendidikan, Pembelajaran dan Teknologi", Vol. 3 no. 1, 2019. 
Model Pembelajaran Group Investigation. (Online). http://allforedu.blogspot.com/2012/06/kelebihan-dan-kekuranganpembelajaran html. diakses pada 15 Oktober 2019.

Slavin, Robert E. (2010). Cooperative Learning. Bandung : PT. Nusa Media.

Sutirman. (2013). Media dan Model-Model Pembelajaran Inovatif. Yogyakarta: Graha Ilmu.

Syafiuddin Shobirin, M. dan M. Faridl Darmawan, "Pengembangan Pembelajaran Kitab Kuning Di Pesantren Luhur Malang", dalam Jurnal JoEMS (Jounal of Education and Management Studies). Vol. 2, No. 1, 15-24, 2019. 